\title{
Smoothened Homolog
}

National Cancer Institute

\section{Source}

National Cancer Institute. Smoothened Homolog. NCI Thesaurus. Code C29980.

Smoothened homolog (787 aa, $\sim 86 \mathrm{kDa}$ ) is encoded by the human SMO gene. This protein plays a role in the modulation of hedgehog signaling pathways. 